\title{
Influence of Different Drinks on the Colour Stability of Dental Resin Composites
}

\author{
Fulya Toksoy Topcua \\ Gunes Sahinkesen ${ }^{\mathrm{a}}$ \\ Kivanc Yamanel ${ }^{\mathrm{b}}$ \\ Ugur Erdemirc \\ Elif Aybala Oktay ${ }^{a}$ \\ Seyda Ersahana
}

\section{ABSTRACT}

Objectives: The objective of this study was to evaluate the discolouration effects of artificial saliva, granule lemon juice, coffee (without sugar), coca cola, sour cherry juice, fresh carrot juice and red wine on resin-based composite materials that are commonly used in restorative dentistry.

Methods: Colour of four brands of resin composites (Filtek Z 250 (3M Espe), Filtek Supreme (3M Espe), Quadrant (Cavex), Charisma (Heraeus-Kulzer)) of A2 shade was measured after one day of immersion in eight different solutions. Colour measurements were obtained by using a XL20 Trismus Colourimeter and colour differences $(\Delta \mathrm{E})$ were estimated. For statistical evaluation, analysis of variance (ANOVA), Dunnett and Tukey tests were used at a significance level of 0.05.

Results: For the four restorative materials tested, the lowest $\Delta \mathrm{E}$ values were observed in the artificial saliva, while $\Delta \mathrm{E}$ values were the highest in red wine group. When comparing the four different restorative materials, Filtek Supreme exhibited the least colour changes whereas Filtek Z250 was the least colour-stable.

Conclusions: Dental resin composites and drinking solutions were significant factors that may affect the colour stability. After immersion for one day, all materials showed visible colour changes. The red wine solution exhibited more staining than others in three groups. Filtek Supreme showed significantly the least colour change due to its nano particle sizes. (Eur J Dent 2009;3:50-56)

Key words: Colour; Composite; Drink.

a Gulhane Military Medical Academy, Dental Sciences Center, Department of Conservative Dentistry and Endodontics, Ankara, Turkey.

b Baskent University, Faculty of Dentistry, Department of Conservative Dentistry, Ankara, Turkey. Istanbul University, Faculty of Dentistry, Department of Conservative Dentistry and Endodontics, Istanbul, Turkey.

- Corresponding author: Fulya Toksoy Topcu Gulhane Askeri Tip Akademisi, Dis Hekimligi Bilimleri Merkezi, Dis Hastaliklari ve Tedavisi AD, 06018, Etlik, Ankara, Turkey. Phone: + 903123046033 Fax: + 903123046020 E-mail: fulyatoksoydayahoo.com

\section{INTRODUCTION}

Aesthetic failure is one of the most common reasons for the replacement of restorations. A good combination of the tooth colour and the initial colour of the material before curing is an important clinical factor for a successful outcome. Nonetheless, this combination must remain after the material is completely cured and throughout the restoration's life-time. Discolouration of tooth-coloured, resin-based materials may be caused by intrinsic or extrinsic factors. ${ }^{1,2}$ The 
intrinsic factors involve the discolouration of the resin material itself, such as the alteration of the resin matrix and of the interface of the matrix and the fillers. Chemical discolouration has been attributed to a change or oxidation in the amine accelerator, oxidation in the structure of the polymer matrix, and oxidation of the unreacted pendant methacrylate groups., ${ }^{3,4}$

Extrinsic factors for discolouration include staining by adsorption or absorption of colourants as a result of contamination from exogenous sources. The degree of discolouration from exogenous sources varies according to the oral hygiene, the eating-drinking and smoking habits of the patients. ${ }^{5,6}$

The staining of polymeric materials by coloured solutions, coffee and tea, nicotine, and beverages has been reported in many previous studies. ${ }^{1-7}$ These substances can lead to yellowbrown stains in teeth as well as on the surfaces of the resin composites. ${ }^{8}$

The measurement of colour is based upon digital expression of a colour obtained from an object. Generally, colour differences are demonstrated by two different systems; Munsell colour system and Standard Commission International de L'Eclairage Colour System. According to the CIE-Lab system recommended by the American Dental Association; all colours in nature are obtained by the mixture of three basic colours: red, blue and green. ${ }^{9-12}$

The purpose of this study was to evaluate the staining capacity of different types of resin-based composite materials upon exposure to artificial saliva, granule lemon juice, coffee (without sugarl, coca cola, sour cherry juice, fresh carrot juice and red wine. The hypothesis of this study was that staining capacity of the resin composite materials is related to the type of the staining solution used.

\section{MATERIALS AND METHODS}

Eight different solutions (distilled water, artificial saliva, granule lemon juice, coffee (without sugar), coca cola, sour cherry juice, fresh carrot juice, red winel and their effects on the colour change of four A2 shade resin composites were evaluated Filtek Z 250 (3M Espe, St. Paul, MN, USA), Filtek Supreme (3M Espe), Quadrant (Cavex, Holland BV, Netherlands), and Charisma
(Heraeus-Kulzer, Gmbh, Wehrheim, Germany). The restorative materials and staining solutions used in this study are shown in Tables 1 and 2 .

One hundred and sixty disk samples (Forty of each material at a diameter of $15 \mathrm{~mm}$ and a thickness of approximately $2 \mathrm{~mm}$ ) were prepared using a metal mold. The mold with the composite resin was held between 2 glass slides each covered with a transparent polyester strip (Mylar, DuPont, Wilmington, Del., USA) and the microscope slides were gently pressed together to remove excess material. All specimens were polymerized by a LED light-curing unit Elipar Free Light 2 (3M ESPE, St. Paul, MN, USA) with light intensity of $1000 \mathrm{~mW} / \mathrm{cm}^{2}$, using 20 seconds of exposure to top and bottom surfaces, respectively. The distance between the light source and the specimen was standardized by the use of a $1 \mathrm{~mm}$ glass slide. The end of the light guide was in contact with the cover glass during the light polymerization process. On completion of specimen fabrication, the disks were randomly divided into eight groups $(n=5)$. For the purpose of surface standardization, the specimens were ground wet with 1000-grit silicon carbide abrasive paper for 10 seconds on a 300-rpm grinding machine (Buehler Metaserv, Buehler, Germany). The top surfaces of all specimens were then polished with fine and superfine polishing disks (Sof-lex, 3M, ESPE) with a low-speed handpiece. Then all prepared specimens were stored in distilled water at $37^{\circ} \mathrm{C}$ for 24 hours for rehydration and completion of the polymerization. The colours of all specimen groups were measured before exposure to staining medias with a XL-20 Tristimulus Colorimeter (Gardner Lab. Inc., Bethesda, Maryland, USAl using CIE (Commission International de l' Eclairage) L*a*b* relative to standard illuminant $A$, against a white background.

Five randomly selected disk specimens from each material were immersed in each of the eight staining solutions indicated in Table 2 at $37^{\circ} \mathrm{C}$ and for 24 hours. The distilled water group was used as a control. After 24 hours, the specimens were rinsed with distilled water and blotted dry with a tissue paper before re-measurements.

All colour testing were carried out according to the CIE-Lab-colour system with a XL-20 Tristimulus Colorimeter (Gardner Lab. Inc., 
Bethesda, Maryland, USA). Values were recorded using the Commission International de l' Eclairage $L^{*} a^{*} b$ colour system (1). The CIE (Commission International de l' Eclairagel system uses the three dimensionless colorimetric measurements. $L^{*}$ characterizes the lightness of the colour and can be ranged between 0 (dark) and 100 (light); $a^{*}$ defining a colour on a red-green axis; and $b^{*}$ describing the blue part of the colour. For each sample, three repeated measurements were taken to determine the colorimetric values. The mean values of $\Delta \mathrm{L}, \Delta \mathrm{a}$ and $\Delta \mathrm{b}$ after three measurements were automatically calculated by colorimeter and recorded. The total colour difference $\Delta \mathrm{E}$ for each disk sample was calculated using the following equation:

$\sqrt{\Delta \mathrm{E}=\left(\Delta \mathrm{L}^{*}\right)^{2}+\left(\Delta \mathrm{a}^{*}\right)^{2}+\left(\Delta \mathrm{b}^{*}\right)^{2}}$

\section{Statistical analysis}

SPSS for Windows V. 12.0 was used for statistical analysis. Descriptive statistics were shown as Mean $\pm S D$. To evaluate the differences between different materials and staining solutions, Univariete ANOVA was used. For the comparison with the control group Dunnett test and for the comparison of the other groups Tukey test was used at a significance level of .05.

\section{RESULTS}

When discolouration of different materials is considered, overall maximum discolouration was seen in Filtek $\mathrm{Z} 250(\Delta \mathrm{E}=2.15+0.95)$ and minimum in Filtek Supreme $(\Delta \mathrm{E}=0.88+0.4)$. Among solutions in which specimens were kept; maximum discolouration was seen with red wine $(\triangle E=2.29+1.07)$ and minimum in artificial saliva $(\Delta \mathrm{E}=1.35+0.61)$ (Table 3). The difference between

Table 1. Name, material type and manufacturer of the tested resin-based composites.

\begin{tabular}{lcc}
\hline Product & Material Type & Manufacturer \\
\hline Filtek Supreme & Nanocomposite & 3M ESPE (St. Paul, MN, USA) \\
Filtek Z 250 & Micro-hybrid composite & 3M ESPE (St. Paul, MN, USA) \\
Charisma & Micro-hybrid composite & Heraeus-Kulzer (Wehrhein, Germany) \\
Quadrant & Hybrid composite & Cavex (Holland BV, Netherlands) \\
\hline
\end{tabular}

Table 2. Staining solutions used in study.

\begin{tabular}{|c|c|c|}
\hline Product & Chemistry & Manufacturer \\
\hline Artificial Saliva & $\begin{array}{l}1.160 \mathrm{~g} / \mathrm{L} \text { sodium chloride, } 0.600 \mathrm{~g} / \mathrm{L} \text { calcium } \\
\text { chloride, } 0.600 \mathrm{~g} / \mathrm{L} \text { potassium phosphate, } 1.491 \\
\mathrm{~g} / \mathrm{L} \text { potassium chloride, } 0.050 \mathrm{~g} / \mathrm{L} \text { sodium flouride, } \\
\text { trace of sodium hydroxide to } \mathrm{pH} 7 \text {. }\end{array}$ & $\begin{array}{l}\text { Ankara -Turkey } \\
\text { (Pharmaceutical } \\
\text { Compounding) }\end{array}$ \\
\hline Granule Lemon Juice & $200 \mathrm{~g} / 200 \mathrm{ml}$ distilled water & Tang/Turkey \\
\hline Coffee (without sugar) & $5 \mathrm{~g}$ coffee $200 \mathrm{ml}$ distilled water & Nescafe/ Spain \\
\hline Coca Cola & $\begin{array}{l}\text { Water, sugar, caramel, orthophosphoric acid, } \\
\text { caffein, cola extract. } 200 \mathrm{ml}\end{array}$ & Pepsi Cola/ Turkey \\
\hline Sour cherry juice & $200 \mathrm{ml}$ & Cappy/ Turkey \\
\hline Fresh carrot juice & $200 \mathrm{ml}$ & Ankara,Turkey \\
\hline Red wine & $200 \mathrm{ml}$ & $\begin{array}{c}\text { Kalecik karası, Ankara, } \\
\text { Turkey }\end{array}$ \\
\hline Distilled water & $200 \mathrm{ml}$ & Ankara -Turkey \\
\hline
\end{tabular}


the means $\Delta \mathrm{E}$ of the materials and the solutions is shown in Table 3. When levels of changes between materials have been compared in groups of two, the differences between the groups was found to be statistically significant $(P<.001)$.

The difference between the solutions was compared statistically and all solutions' staining capacity was found to be significantly different from the control group $(P<.001)$. The difference between red wine and coffee, which together caused the highest discolouration, and the other groups was found to be statistically significant $(\mathrm{P}<.001)$.

The difference between sour cherry juice, granule lemon juice and fresh carrot juice was not significant $(P>.05)$, while the difference with the other groups was significant $(P<.001)$.

The most pronounced colour changes were seen with Filtek Z250 in coffee, cola, cherry juice, carrot juice and red wine. In granule lemon juice and artificial saliva, most of the colour changes occurred with Charisma. The least colour changes were seen with coffee, cola, cherry juice, red wine and artificial saliva in Filtek Supreme and with lemon juice in Charisma and with carrot juice in Quadrant.

\section{DISCUSSION}

The discolouration of tooth coloured resinbased composite materials can be a reason for the replacement of dental restorations in aesthetic areas. ${ }^{13}$ This process concerns patient and dentist and consumes time and money.

Colour stability has previously been studied in vitro for a variety of aesthetic restorative materials. ${ }^{14-16}$ Discolouration can be evaluated visually or by instrumental techniques. ${ }^{17}$ The system for measuring chromacity was chosen to record colour differences because it is well suited for the determination of small colour differences. ${ }^{8}$ Tristimulus colorimeters are capable of detecting colour differences below the threshold of visual perception. ${ }^{17}$ The value of $\Delta \mathrm{E}^{*}$ represents relative colours changes that an observer might report for the materials after immersion or between time periods. Thus $\Delta \mathrm{E}^{*}$ is more meaningful than the individual $L^{*}, a^{*}, b^{*}$ values. $^{2}$

When differences in colour matching between human-eye assessment and colorimetric were compared, colour difference was perceptible when $\Delta \mathrm{E}$ values were greater than three. ${ }^{18}$

In the present study, red wine caused the most severe discolouration results with 3 of the 4 resin composite materials tested. We selected a red

Table 3. Staining solutions used in study.

\begin{tabular}{|c|c|c|c|c|c|c|c|}
\hline & $\begin{array}{l}\text { Quadrant } \\
\text { Mean士SD }\end{array}$ & $\begin{array}{l}\text { Charisma } \\
\text { Mean } \pm \text { SD }\end{array}$ & $\begin{array}{c}\text { Filtek Z } \\
250 \\
\text { Mean士SD }\end{array}$ & $\begin{array}{c}\text { Filtek } \\
\text { Supreme } \\
\text { Mean } \pm S D\end{array}$ & $P$ & $\begin{array}{c}\text { Pairwise } \\
\text { comparison }\end{array}$ & $\begin{array}{c}\text { Total } \\
\text { MeanะSD }\end{array}$ \\
\hline $\begin{array}{l}\text { Control } \\
\text { (distilled water) }\end{array}$ & $0.15 \pm 0.04$ & $0.16 \pm 0.02$ & $0.22 \pm 0.03$ & $0.11 \pm 0.04$ & 0.893 & & $0.16 \pm 0.03$ \\
\hline Coffee & $1.67 \pm 0.01$ & $1.91 \pm 0.01$ & $2.81 \pm 0.01$ & $1.22 \pm 0.01$ & $<0.001$ & $b, c, d, e, f$ & $1.90 \pm 0.62$ \\
\hline Granule lemon juice & $1.20 \pm 0.06$ & $1.08 \pm 1.91$ & $1.90 \pm 0.09$ & $1.44 \pm 0.06$ & 0.002 & $b, d, e, f$ & $1.41 \pm 0.34$ \\
\hline Cola & $1.46 \pm 0.04$ & $1.32 \pm 1.08$ & $2.06 \pm 0.13$ & $0.59 \pm 0.02$ & $<0.001$ & $b, c, d, e, f$ & $1.36 \pm 0.56$ \\
\hline Sour cherry juice & $1.11 \pm 0.04$ & $1.36 \pm 1.32$ & $2.40 \pm 0.07$ & $1.00 \pm 0.01$ & $<0.001$ & $a, b, d, e, f$ & $1.47 \pm 0.59$ \\
\hline Fresh carrot juice & $0.95 \pm 0.01$ & $1.09 \pm 1.36$ & $2.34 \pm 0.13$ & $1.29 \pm 0.01$ & $<0.001$ & $b, c, d, f$ & $1.42 \pm 0.59$ \\
\hline Red Wine & $2.39 \pm 0.04$ & $2.77 \pm 0.06$ & $3.34 \pm 0.01$ & $0.66 \pm 0.03$ & $<0.001$ & $a, b, c, d, e, f$ & $2.29 \pm 1.07$ \\
\hline Artificial saliva & $1.17 \pm 0.12$ & $1.36 \pm 2.77$ & $2.32 \pm 0.02$ & $0.86 \pm 0.01$ & $<0.001$ & $a, b, e, f$ & $1.35 \pm 0.61$ \\
\hline Total & $1.24 \pm 0.65$ & $1.32 \pm 0.76$ & $2.15 \pm 0.95$ & $0.88 \pm 0.045$ & $<0.001$ & $a, b, e, f$ & $1.41 \pm 0.86$ \\
\hline
\end{tabular}
a: Quadrant- Charisma
b: Quadrant - Filtek Z 250
c: Quadrant -Filtek Supreme
d: Charisma - Filtek Z 250
e: Charisma - Filtek Supreme
f: Filtek Z 250- Filtek Supreme 
wine, which is a dark burgundy and that contains 12 percent alcohol by volume. Several studies have reported that alcohol facilitates staining by softening the resin matrix of the composites. ${ }^{19-21}$

The most staining solution was the red wine for Filtek $Z 250\left(\Delta E^{*}=3.3\right)$, Charisma $\left(\Delta E^{*}=2.8\right)$ and Quadrant $\left(\Delta E^{*}=2.4\right)$ but not for Filtek Supreme $\left(\Delta \mathrm{E}^{*}=0.7\right)$ in which the most staining solution was granule lemon juice $\left(\Delta E^{*}=1.4\right)$. The staining capacity of coffee, granule lemon juice, Coca cola, sour cherry juice, fresh carrot juice and artificial saliva were less than that of red wine for Filtek $Z$ 250, Charisma and Quadrant.

The results show that the effect of coffee on the colour change was similar to that of red wine. Coffee may stain both by adsorption and by absorption of its colorants onto/into the organic phase of the resin composites. ${ }^{22}$

The staining observed in studies are usually those that occur on the surface. This is because of the hydrophobic monomers in composite resins. ${ }^{10,23}$ For instance, UDMA based monomers display lower staining values compared to other dimethacrilate based monomer types. ${ }^{8}$ This may be accounted for low viscosity and low water absorption of urethane dimethacrilate and its successful polymerization with visible light. ${ }^{24,25}$

It was found that incorporation of greater amounts of TEGDMA resulted in an increase in water uptake in Bis-GMA based resins, ${ }^{26}$ and Tarumi et $a^{27}$ reported that this was due to increased surface hydrophilicity. Hydrophilic groups such as the ethoxy group in TEGDMA are thought to show affinity with water molecule by hydrogen bonding to oxygen. ${ }^{28}$

An explanation for the differences in optical properties due to water exposure might be found in the materials' composition and the way they are affected by environmental conditions. It is known from recent studies that resin-based composites allow water penetration to matrix or filler-matrix interface. ${ }^{29}$ As it is assumed that the resin component is a source of discolouration, one would expect that a high volume fraction of the resin correlates with a high prospect for discolouration. ${ }^{14}$ From this study, the amount of matrix resin could not be directly associated with the degree of colour shift (filler load by volume for Quadrant Universal LC is 60\%, for Charisma 64\%, for Filtek Supreme \%59.5 and for Filtek Z $25071 \%$. This is in accordance with the observations of Dietchi et $\mathrm{al}^{22}$ who stated that small differences in filler-resin ratio could not be explained by variations in water absorption.

Patel et $\mathrm{al}^{30}$ investigated the staining capacity of unfilled resins and resin-based composites. Even though unfilled resin has more resin matrix present than does resin based composite, unfilled resin specimens generally exhibited less colour changes than did resin based composite specimens, with the exception of specimens immersed in cola solution. This deviation also demonstrated the critical role of the composition of the staining solution on the colour changes.

The colour shifts may be related to the structure of the resin matrix (Bis-GMA, UDMA and TEGDMA for Quadrant Universal LC, Charisma and Bis-GMA, Bis-EMA and UDMA for Z 250 and Bis-GMA, Bis-EMA, UDMA, TEGDMA for Filtek Supreme). The fact that Filtek Z 250 displayed more discolourations than the other materials in all solutions draws our attention to Bis-EMA, which is present only in its structure. However, that Bis-EMA used instead of TEGDMA present in the other resin composites tested has a more hydrophobic structure than TEGDMA and cannot account for higher staining values of Filtek Z250 in comparison to the other materials.

Large filler particles highly exposed on the surface will produce large surface roughness values. ${ }^{31}$ As purported by the manufacturer, Filtek Supreme is a nano composite with a primary $20 \mathrm{~nm}$ silica filler and loosely bonded cluster zirconia/silica particle size ranging from 0.6 to $1.4 \mu \mathrm{m}$. In the present study in order to stimulate clinical situations, Sof-lex contouring and polishing disks were used and Filtek Supreme has smaller filler particle size, and this material may have less surface roughness than the other tested materials demonstrated significantly less colour changes.

It has been suggested that silanization of filler particles plays an important role in discolouration as does the type of the resin used in the resinbased composites. This is due to the fact that silane has high water absorption levels. ${ }^{32}$ High staining values of Filtek Z 250 may be attributed to the high proportion of silane present in the structure of the material.

We demonstrated that the effect of the staining 
solutions was different for various materials. These results are in agreement with the previous studies. ${ }^{33-36}$ In spite of the short staining period of the present study (24 hours) coffee and red wine stained seriously some of the tested materials. In the previous studies that tested longer staining periods, it has been stated that after 7 days or longer immersion, materials had visually perceptible colour changes. ${ }^{2,14,33}$ Because of that reason, the drinking habits of the patients must be considered while choosing restorative resinbased materials especially on the anterior region of the mouth.

\section{CONCLUSIONS}

The colour stability of four resin-based composite materials was evaluated after 24 hours of immersion in various staining solutions. Within the limitations of this study, the following conclusions were drawn:

1. Nano composite material, Filtek Supreme was found to have the least discolouration among the all restorative materials tested. These differences were found to be significantly different.

2. Colour change values of artificial saliva, granule lemon juice, coffee, coca cola, sour cherry juice, fresh carrot juice and red wine groups of resin-based composites were smaller than or equal to $\Delta \mathrm{E}=3$. Red wine and coffee have higher colour change than others.

3. Red wine produced the most discolouration results in three of the four resin based composite materials tested.

\section{REFERENCES}

1. Um CM, Ruyter IE. Staining of resin-based veneering materials with coffe and tea. Quintessence Int 1991;22:377386.

2. Yannikakis SA, Zissis AJ, Polyzois GL, Caroni C. Colour stability of provisional resin restorative materials. J Prosthet Dent 1998;80:533-539.

3. Ruyter IE. Composites-characterization of composite filling materials: reactor response. Adv Dent Res 1988;2:122-129.

4. Asmussen E. Factors affecting the colour stability of restorative resins. Acta Odontol Scand 1983;41:11-18.

5. Satou N, Khan AM, Matsumae I, Satou J, Shintani H. In vitro colour change of composite- based resins. Dent Mater 1989;5:384-387.
6. Raptis CN, Powers JM, Fan PL, et al: Staining of composite resins by cigarette smoke. J Oral Rehabil 1982;9:367-371.

7. Gross MD, Moser JB. A colourimetric study of coffee and tea staining of four composite resins. J Oral Rehabil 1977;4:311-322.

8. Khokhar ZA, Razzoog ME, Yaman P. Colour stability of restorative resins. Quintessence Int 1991;22:733-737.

9. $\mathrm{CIE}$ (Commission International del'Eclairage). Colourimetry technical report. CIE Publication No.15, 2nd ed., Vienna, Austria: Bureau Central de la CIE, 1986, (corrected reprint 1996).

10. Canay \$, Hersek N, Tulunoḡlu I, Uzun G. Evaluation of colour and hardness changes of soft lining materials in food colourant solutions. J Oral Rehabil 1999;26:821-829.

11. Seghi RR, Gritz MD, Kim J. Colourimetric changes in composites resulting from visible-light-initiated polymerization. Dent Mater 1990;6:133-137.

12. Okubo SR, Kanawati A, Richards MW, Childress S. Evaluation of visual and instrument shade matching. $J$ Prosthet Dent 1998;80:642-648.

13. Wilson NH, Burke FJ, Mjor IA. Reasons for placement and replacement of restorations of direct restorative materials by a selected group of practitioners in the United Kingdom. Quintessence Int 1997;28:245-248.

14. Inokoshi S, Burrow MF, Kataumi M, Yamada T, Takatsu T. Opacity and colour changes of tooth coloured restorative materials. Oper Dent 1996;21:73-80.

15. Leibrock A, Rosentritt M, Lang R, Behr M, Handel G. Colour stability of visible light-curing hybrid composites. Eur $J$ Prosthod Restor Dent 1997;5:125-130.

16. Vargas MA, Kirchner HL, Diaz-Arnold AM, Beck VL. Colour stability of ionomer and resin composite restoratives. Oper Dent 2001;26:166-171.

17. Lee YK, Lim BS, Kim CW. Influence of illuminating and viewing aperture size on the colour of dental resin composites. Dent Mater 2004;20:116-123.

18. Yap AU, Sim CP, Loh WL, Teo JH. Human-eye versus computerized colour matching. Oper Dent 1999;24:358363.

19. Abu-Bakr N, Han L, Okamoto A, Iwaku M. Colour stability of compomer after immersion in various media. $J$ Esthet Dent 2000;12:258-263.

20. Ferracane JL, Berge HX, Condon JR. In vitro aging of dental composites in water: effect of degree of conversion, filler volume and filler-matrix coupling. J Biomed Mater Res 1995;42:465-472.

21. Deepa CS, Krishnan VK. Effect of resin matrix ratio, storage medium and time upon the physical properties of a radiopaque dental composite. J Biomater Appl 2000;14:296315. 
22. Van Groeningen G, Jongebloed W, Arends J. Composite degradation in vivo. Dent Mater 1986;2:225-227.

23. Dietschi D, Campanile G, Holz J, Meyer JM. Comparison of the colour stability of ten new-generation composites: An in vitro study. Dent Mater 1994;10:353-362.

24. Douglas $W H$, Craig RG. Resistance to extrinsic stains by hydrophobic composite resin systems. J Dent Res 1982;61:41-43.

25. Khan Z, von Fraunhofer JA, Razavi R. The staining characteristics, transverse strength and microhardness of a visible light cured tenture base material. $J$ Prosthet Dent 1987:57:384-386.

26. Kalachandra S, Turner DT. Water sorption of polymethacrylate networks: Bis-GMA/TEGDMA copolymers. J Biomed Mater Res 1987;21:329-338.

27. Mazato S, Tarumi H, Kato S, Ebisu S. Water sorption and colour stability of composites containing the antibacterial monomer MDPB. J Dent 1999;27:279-283.

28. Arima T, Hamada T, McCabe JF. The effects of crosslinking agents on some properties of HEMA-based resins. J Dent Res 1995;74:1597-1601.

29. Oysaed H, Ruyter IE. Water sorption and filler characteristic of composites for use in posterior teeth. J Dent Res 1986;65:1315-1318.

30. Patel SB, Gordan VV, Barrett AA, Shen C. The effect of surface finishing and storage solutions on the colour stability of resin-based composites. J Am Dent Assoc 2004;135:587-594

31. Maalhagh-Fard A, Wagner WC, Pink FE, Neme AM. Evaluation of surface finish and polish of eight provisional restorative materials using acrylic bur and abrasive disc with and without pumice. Oper Dent 2003;28:734-739.

32. Rueggeberg FA, Craig RG. Correlation of parameters used to estimate monomer conversion in a light cured composite. J Dent Res 1988;67:932-937.

33. Villalta P, Lu H, Okte Z, Garcia-Godoy F, Powers JM. Effects of staining and bleaching on colour change of dental composite resins. J Prosthet Dent 2006;95:137-142.

34. Guler AU, Yilmaz F, Kulunk T, Guler E, Kurt S. Effects of different drinks on stainability of resin composite provisional restorative materials. J Prosthet Dent 2005;94:118-124.

35. Türkün LS, Leblebicioḡlu EA. Stain retention and surface characteristics of posterior composites polished by onestep systems. Am J Dent 2006; 19:343-347.

36. Türkün LS, Türkün M. Effect of bleaching and repolishing procedures on coffee and tea stain removal from three anterior composite veneering materials. J Esthet Restor Dent 2004; 16:290-301. 